\title{
On the Ongoing Evolution of Very High Frequency Power Supplies
}

Knott, Arnold; Andersen, Toke Meyer; Kamby, Peter; Madsen, Mickey Pierre; Kovacevic, Milovan; Andersen, Michael A. E.

Published in:

Proceedings of The IEEE Applied Power Electronics Conference and Exposition

Link to article, DOI:

10.1109/APEC.2013.6520649

Publication date:

2013

Link back to DTU Orbit

Citation (APA):

Knott, A., Andersen, T. M., Kamby, P., Madsen, M. P., Kovacevic, M., \& Andersen, M. A. E. (2013). On the Ongoing Evolution of Very High Frequency Power Supplies. In Proceedings of The IEEE Applied Power Electronics Conference and Exposition: APEC (pp. 2514-2519). IEEE.

https://doi.org/10.1109/APEC.2013.6520649

\section{General rights}

Copyright and moral rights for the publications made accessible in the public portal are retained by the authors and/or other copyright owners and it is a condition of accessing publications that users recognise and abide by the legal requirements associated with these rights.

- Users may download and print one copy of any publication from the public portal for the purpose of private study or research.

- You may not further distribute the material or use it for any profit-making activity or commercial gain

- You may freely distribute the URL identifying the publication in the public portal

If you believe that this document breaches copyright please contact us providing details, and we will remove access to the work immediately and investigate your claim. 


\title{
On the Ongoing Evolution of Very High Frequency Power Supplies
}

\author{
Arnold Knott*, Toke M. Andersen*, Peter Kamby*, Mickey P. Madsen*, Milovan Kovacevic*, Michael A.E. Andersen* \\ *Technical University of Denmark \\ Ørsteds Plads, bygning 349 \\ 2800 Kongens Lyngby \\ Denmark \\ Email: akn@elektro.dtu.dk
}

\begin{abstract}
The ongoing demand for smaller and lighter power supplies is driving the motivation to increase the switching frequencies of power converters. Drastic increases however come along with new challenges, namely the increase of switching losses in all components. The application of power circuits used in radio frequency transmission equipment helps to overcome those. However those circuits were not designed to meet the same requirements as power converters. This paper summarizes the contributions in recent years in application of very high frequency (VHF) technologies in power electronics, describes the remaining challenges and shows results of the recent advances, among others a $120 \mathrm{MHz}, 9 \mathrm{~W}$ LED driver with $89 \%$ efficiency.
\end{abstract}

\section{INTRODUCTION}

The continuing trend of miniaturization in industrial and consumer electronics is continuously driving a demand for smaller power supplies. Weight and cost reduction demands accompany this trend. Within power supplies the major size, weight and cost drivers are typically the passive components. Increasing the switching frequency of power converters can reduce the size, weight and therefore the cost of those. For substantial size and weight reduction, the switching frequencies are increased up to the very high frequency (VHF) band (30 $\mathrm{MHz}$ to $300 \mathrm{MHz}$ ), which leads to a merge in circuit technologies used in radio frequency transmitters [1]-[6] and the classical power electronics circuits.

The VHF amplifiers are designed for DC-AC conversion, where the AC simultaneously is the switching frequency. Generally those circuits [1], [2] drive a known load impedance, typically a $50 \Omega$ antenna. The most efficient standard representatives of radio frequency amplifiers are class-E [3], [4] and class-F [5], [6], where Class-E applies zero-voltageswitching (ZVS) and Class-F applies zero-current-switching (ZCS) techniques. Similarly to switch-mode power supplies, those VHF amplifiers convert the constant supply voltages into a high-frequent voltage by operating power semiconductors in the cut-off or saturation region only. The major difference is, that VHF amplifiers do not convert the energy back into a constant voltage or current level.

Numerous research works have been published [7]-[18], filling this gap and making VHF technologies available for power electronics. This paper describes the individual contributions of those in greater detail. However there are still some challenges left, before VHF switch-mode power supplies can relieve their advantages for products in industrial and consumer electronics.

This paper elaborates on the remaining challenges based on previous work and characterizes them in Section II. Section III describes the most recent advances, showing prototypes and measurement results. Section IV concludes the paper.

\section{Challenges of VHF CONVERTERS}

VHF operation of power supplies differs from submegahertz operated power supplies (here called traditional power converters) mainly by the following subjects:

- Electronic components, both active and passive,

- Circuit architectures for power stages and control parts,

- Adjacent behavior, such as electromagnetic compatibility (EMC) and mechanics.

\section{A. Components}

Especially inductive components are size, weight and cost optimization limitations in nowadays power circuits. Simultaneously VHF converters provide a major opportunity to overcome those.

Among the challenges are core losses, skin and proximity effect [19]-[25]. Another challenge within passive components for VHF is the creation of a galvanic isolation barrier [26], [27].

Despite passive components also active components, i.e. the power semiconductors, need to fulfill other requirements than in usual power supplies [28]-[30]. The parasitic components have a big influence on the design of the overall converter, as they are part of the design parameters. Unlike traditional power stages, the parasitic elements are therefore not considered undesired, but form an integral part of the stage. An example is the output capacitance $C_{o s}$ of the power semiconductor in a Class-E based power supply. According to [17] it is dependent on output power $P_{\text {out }}$, input voltage $V_{\text {in }}$ and switching frequency $f_{s w}$ as shown in equation 1 .

$$
P_{\text {out }}=2 \pi^{2} f_{\text {sw }} C_{\text {oss }} V_{\text {in }}^{2}
$$




\section{B. Architectures}

Where traditional power electronics circuits use square wave gate drive signals, the presented VHF converters so far utilized sinusoidal gate drive [16], [31]-[33]. This is mainly due to the input capacitance $C_{i s s}$ of VHF power semiconductors, which require a high peak current at extremely high speed. To consider the drive trapezoidal, the rise and fall times have to be less than $1 \mathrm{~ns}$ [33]. A trapezoidal or square wave drive would minimize the time of the power switch in linear operation and therefore decreases the losses.

The degrees of freedom in terms of modulation principles are less for VHF converters. Whereas power electronics circuits usually use pulse width modulation or phase modulation, the VHF converters efficiency is dependent on those parameters. Therefore they need to be adjusted statically to avoid losses by leaving the ZVS (or ZCS) range. A way to get around this is to apply burst mode control [15], [31], [34]. This method however introduces another low frequency component in the spectrum, which has to be buffered or filtered at both the inand output of the converter. A requirement that enforces the use of bulky components and therefore is counterproductive to the intended advantages of VHF converters in the first place. While the VHF converters offer good possibilities for fast transient regulations, their low frequency control performance is limited by intrinsic bandpass behaviors through serial capacitors. Even though some rectifiers are available with parallel capacitances and impedance transformation [17], [35], more suitable architectures are missing. Thereby it needs to be taken into account, that the original VHF power circuits are designed to match a defined load (typically the impedance of the antenna) and therefore impedance transformation circuits can be realized in a passive way. Power converters however are connected to highly varying loads, i.e. load circuit in idle - drawing no energy from the supply - and full load demanding the maximum output from the supply. Therefore active and lossless impedance matching circuits are required. Having such circuits at hand opens for utilization of the high gain bandwidth in VHF converters for line and load regulation.

\section{Adjacencies}

Lastly the interaction of VHF converters with its physical environment is different than the one of traditional power converters.

On the one hand, the electromagnetic interaction between circuits increases, the higher the relevant frequencies are [36][39]. Fields are distributed easier both inside the converter and to its surroundings. The electrical behavior also becomes highly dependent on electromechanical interfaces, such as cooling and housing. However the harmonics of the resonant waveforms are falling faster, than the harmonics in hard switched traditional power converters [18]. Also the harmonics of the fundamental switching frequency are spaced wider. That means the distance can be used to place strategically important EMC bands, dependent on the application.

On the other hand, the carefully adjusted operating points of VHF converters (for efficiency purposes) are highly dependent on temperature [17], [18]. Adaptive mechanisms for ensuring optimal operation over industry standard temperature ranges are yet to come.

\section{RECENT ADVANCES}

Despite those challenges recent research results enhanced the state-of-the art in VHF converters and gives hope to overcome the remaining challenges.

The Class-E based power circuits allow for a second degree of soft switching. Despite turning the power switches on, when the voltage across them is zero (ZVS) or off, when the current through them is zero (ZCS), also the derivatives of these signals are taken into account. This is called ZdVS and ZdCS respectively. The technique has been applied to power converters in [17]. Figure 1 shows the full schematic of the power part of the self-oscillating VHF converter (DC-DC) from [17], [32].

Figure 2 shows the simulated waveforms of this converter, where $v_{s}$ and $i_{s}$ are the voltage and the current across and through the switch and $v_{D}$ and $i_{D}$ are voltage and current across and through the rectifier diode. $v_{G}$ is the control signal of the power switch and $V_{o}$ and $V_{i}$ are input and output voltages of the converter. The top graph $v_{s}$ visualizes the optimization of the converter for both ZVS and ZdVS.

Figure 3 is a photograph of the implementation of this converter. The overall efficiency of the $97 \mathrm{MHz}$ converter is $55 \%$.

Due to the tight adjustment of the turn on instance of the power switch for achieving ZVS and ZdVS the degrees of freedom in this converter are low. That limits the input and output voltage ranges. Furthermore the efficiency is not acceptable. In this case, the majority of the losses are due to conduction losses in the power semiconductors.

Suboptimal operation of Class-E converters as described in [4] opened for higher degrees of freedom in the design of Class-E based DC-DC converters. This means, that the ZdVS condition is only fulfilled under nominal load conditions and only ZVS is fulfilled otherwise. The effects of these operation mode as described in [40] has been extended in [18] to LED lighting applications.

Furthermore [18] provides a detailed analysis of the power components parasitics and the effect of their nonlinearities. The most relevant parasitics of the power switch are the input and output capacitances. They are typically highly nonlinear. Figure 4 shows the relative voltage stress of the power switch

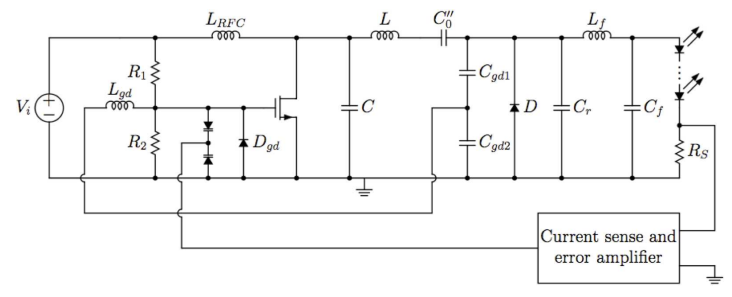

Fig. 1: Complete schematic of a self-oscillating VHF converter [32] with LED load. 
$v_{s}$

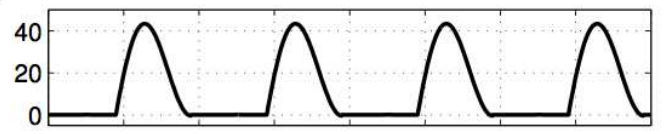

$i_{s}$
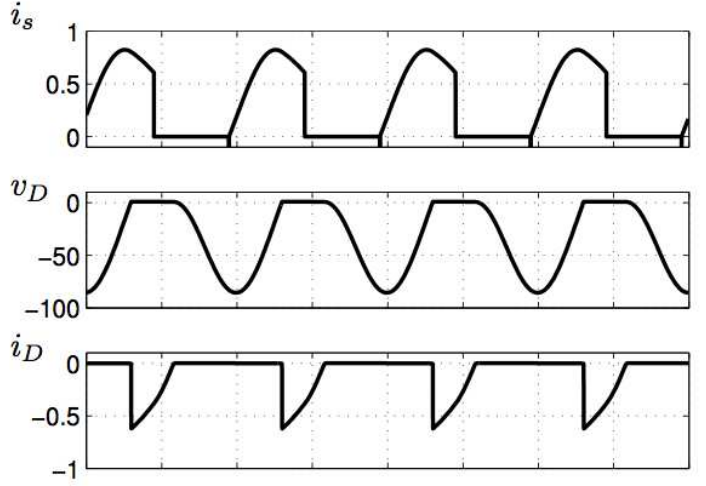

$v_{G}$
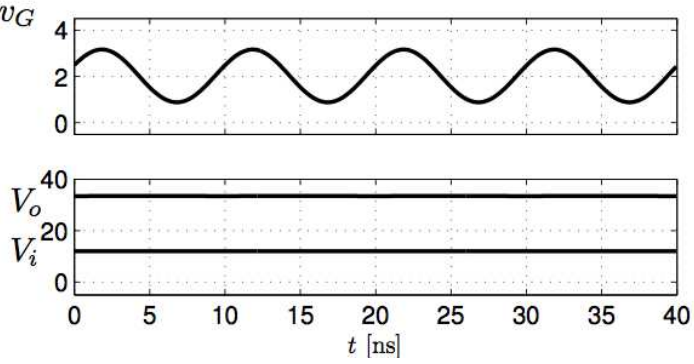

Fig. 2: Simulation of waveforms for a ZVS and ZdVS Class-E based converter from [17].

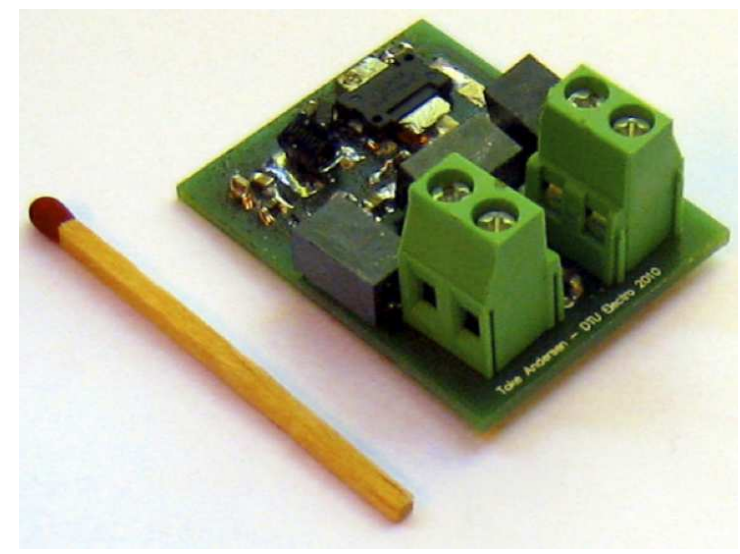

Fig. 3: Photograph of the self-oscillating VHF converter from [32].

as a function of time and junction potential.

The other components of the power stage have been investigated in [18] as well. Thereby most focus is on the inductors, as these are the most volume consuming parts, have the biggest weight and typically a big impact on the overall price of the converter. Therefore the inductors have been integrated as toroids into the printed circuit board (PCB). This process

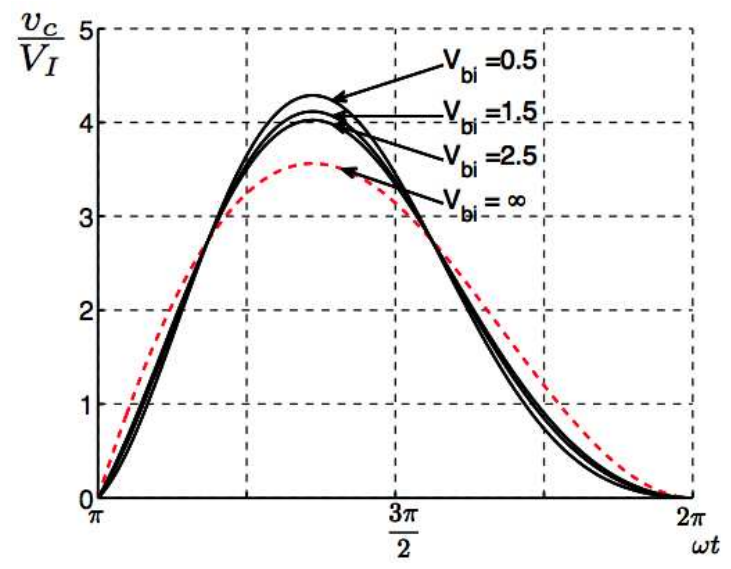

Fig. 4: Voltage stress of the power switch in relation to DC input voltage for a nonlinear output capacitance from [18]. $V_{b i}$ is the junction potential of the process.

is described in [41] and Figure 5 shows the principle.

The resulting converter waveform in the optimal and suboptimal operating regions are shown in Figure 6. The converters efficiency is in the same area as the previous presented. For dealing with the efficiency challenge, [42] compared a number of power switches both in simulation and experiment. Figure 7 shows photographs of the implementations. On top of that an effective line- and load regulation scheme was implemented in those.

Figure 8 shows the implementation of the final prototype with $70 \mathrm{MHz}$ switching frequency. The voltage step-down ratio of the converters is 10 and the output power range is between 1

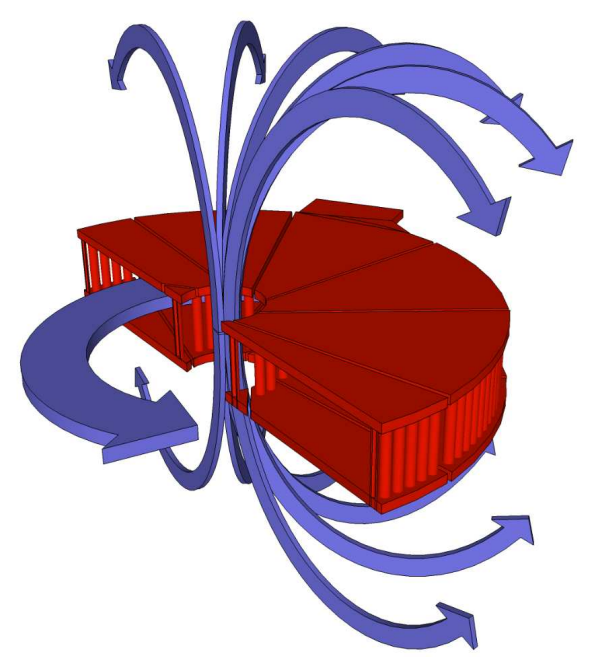

Fig. 5: PCB integrated inductor from [41]. The copper contained in the PCB is shown in red. The blue arrows mark the magnetic field. 


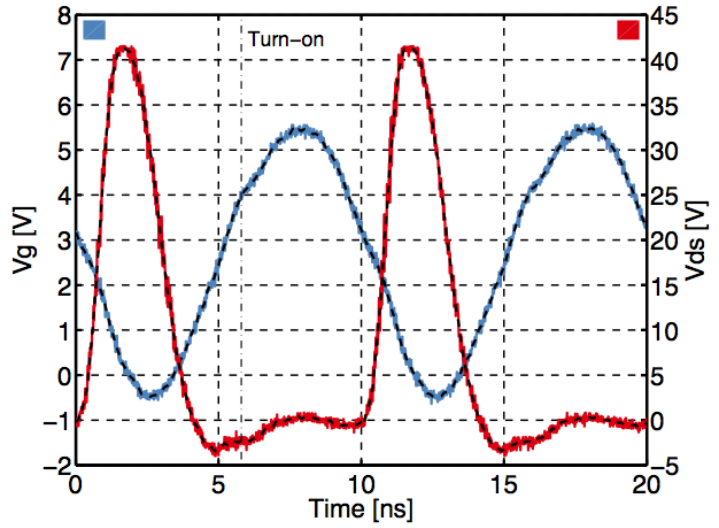

(a) optimal operation

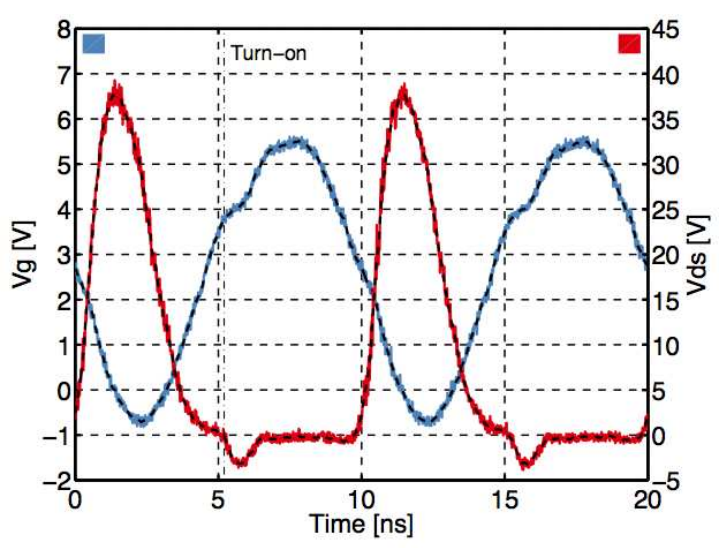

(b) suboptimal operation

Fig. 6: Measurements of gate-source and drain-source voltages $V_{g s}$ and $V_{d s}$ of the power switch and the turn-on instances. Note that the drain-source voltage has an offset of $-0.5 \mathrm{~V}$, due to the oscilloscopes offset.

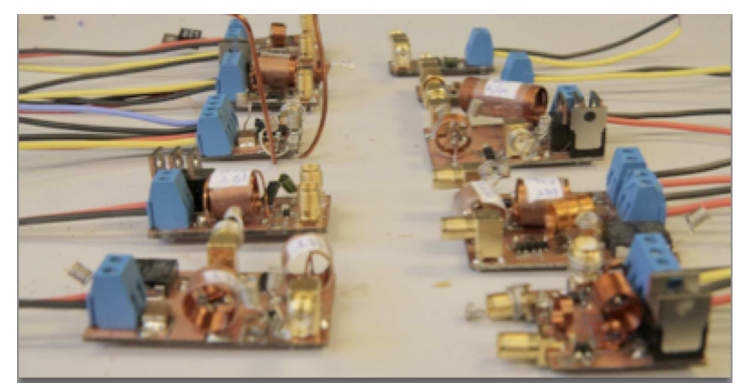

Fig. 7: Photograph of numerous prototypes for comparing measured efficiency with simulations [42].

and $4 \mathrm{~W}$ at an efficiency within this range beyond $70 \%$. Additionally the self-oscillating principle from [17], [32] was applied to an interleaved Class-E converter in [43], resulting into a significant efficiency improvement. The complete schematic is shown in Figure 9. The realized converter is switching at $120 \mathrm{MHz}$, i.e. beyond the FM band, converts

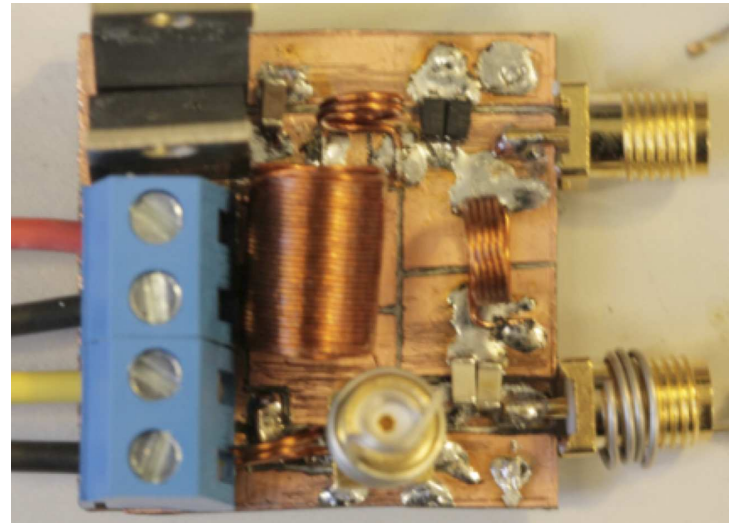

Fig. 8: Photograph of a closed loop low-power VHF converter with an efficiency beyond $70 \%$ from [42]. The TO220 components on the upper left is the dummy load resistance.

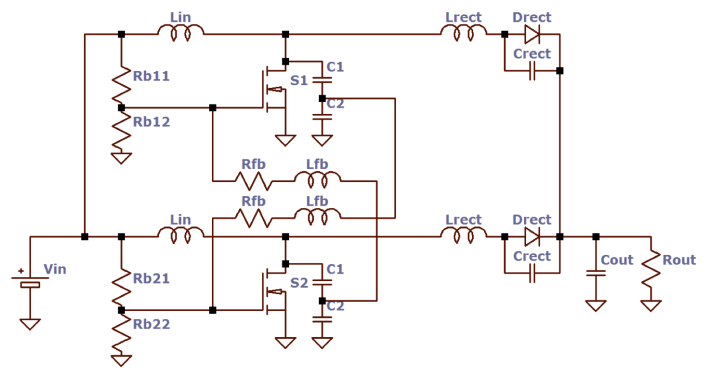

Fig. 9: Full schematic of interleaved Class-E converter from [43].

an input voltage between 6 and $9 \mathrm{~V}$ into an output current between 0.4 and $0.5 \mathrm{~A}$ and has an efficiency between 80 and $89 \%$ within this operation range. The output power range is 3 to $9 \mathrm{~W}$ and the converter is built for LED drive. Figure 10 shows both a SPICE based simulation and a the measurement of the power switches voltage waveforms.

\section{CONCLUSION}

The merge of techniques used in radio communication electronics and power electronics was pointed out. The development through the previous decades has been revisited and recent developments were summarized. Remaining challenges and the latest advances were described. The implementations of numerous VHF converters were presented. Among them are low-power, high-step-down converters with a switching frequency of $70 \mathrm{MHz}$ and an efficiency beyond $70 \%$ as well as a $120 \mathrm{MHz}, 9 \mathrm{~W}$ LED driver with an efficiency up to $89 \%$. Both converters maintain high efficiencies over a wide load range.

\section{REFERENCES}

[1] A. Grebennikov and N.O. Sokal. Switchmode RF power amplifiers. Communications engineering series. Elsevier/Newnes, 2007, ISBN: 9780750679626. 


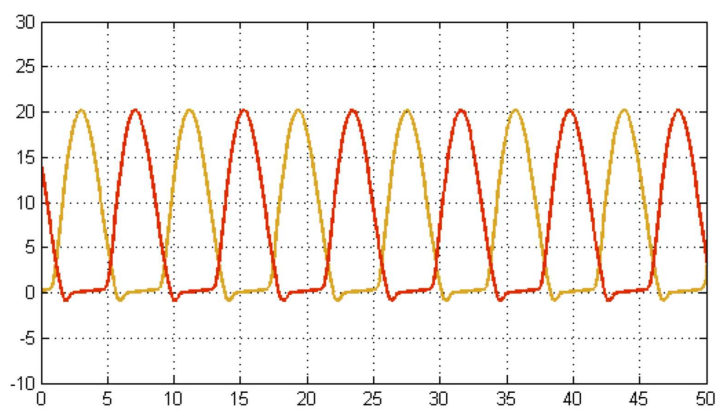

(a) simulated waveforms

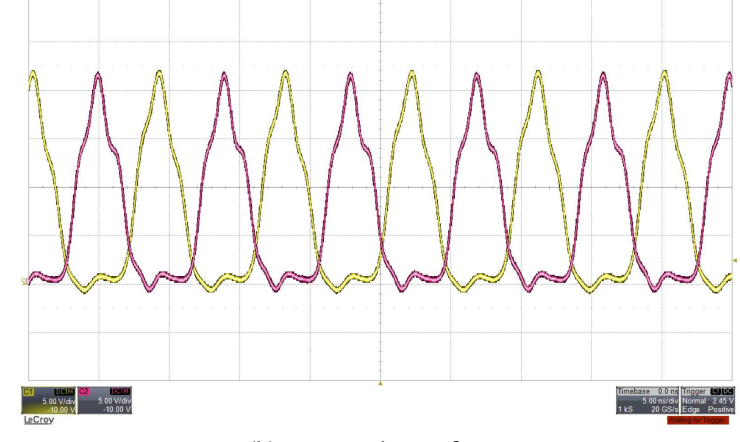

(b) measured waveforms

Fig. 10: Drain-source waveforms of the two power switches in the interleaved converter from [43].

[2] M. Kazimierczuk. RF power amplifiers. Wiley, 2008, ISBN: 9780470779460.

[3] N. O. Sokal, A. D. Sokal. Class E-A new class of high-efficiency tuned single-ended switching power amplifiers. IEEE Journal of Solid-State Circuits, SC-10(3):168-176, June 1975.

[4] N. O. Sokal. Class-E High-Efficiency RF/Microwave Power Amplifiers: Principles of Operation, Design Procedures, and Experimental Verification. Analog Circuit Design, Springer, 2003.

[5] Raab, F.H. Maximum efficiency and output of class-F power amplifiers. IEEE Transactions on Microwave Theory and Techniques, 49(6):11621166, June 2001.

[6] Raab, F.H. Class-F power amplifiers with maximally flat waveforms. IEEE Transactions on Microwave Theory and Techniques, 45(11):20072012, November 1997.

[7] David A. Jackson. Design and Characterization of a Radio-Frequency $\mathrm{dc} / \mathrm{dc}$ PowerConverter. Master's thesis, Massachusetts Institute of Technology, 2005.

[8] James Raymond Warren III. Cell Modulated dc/dc Converter. Master's thesis, Massachusetts Institute of Technology, 2005.

[9] Robert C. N. Pilawa-Podgurski. Design and Evaluation of a Very High Frequency dc/dc Converter. Master's thesis, Massachusetts Institute of Technology, 2007.

[10] Anthony Sagneri. Design of a Very High Frequency dc-dc Boost Converter. Master's thesis, Massachusetts Institute of Technology, 2007

[11] Olivia Leitermann. Radio Frequency dc-dc Converters: Device Characterization, Topology Evaluation, and Design. Master's thesis, Massachusetts Institute of Technology, 2008.

[12] Joshua W. Phinney. Multi-resonant Passive Components for Power Conversion. $\mathrm{PhD}$ thesis, Massachusetts Institue of Technology, May 2005.

[13] Juan Rivas. Radio Frequency $d c-d c$ Power Conversion. $\mathrm{PhD}$ thesis, Massachusetts Institue of Technology, September 2006.

[14] Yehui Han. Circuits and Passive Components for Radio-Frequency Power Conversion. PhD thesis, Massachusetts Institue of Technology, February 2010.
[15] Perreault, D.J.; Jingying Hu; Rivas, J.M.; Yehui Han; Leitermann, O.; Pilawa-Podgurski, R.C.N.; Sagneri, A.; Sullivan, C.R. Opportunities and Challenges in Very High Frequency Power Conversion. Annual IEEE Applied Power Electronics Conference and Exposition, (24):1-14, 2009.

[16] Rivas, J.M. Wahby, R.S. Shafran, J.S. Perreault, D.J. New Architectures for Radio-Frequency DC-DC Power Conversion. IEEE Transactions on Power Electronics, Vol. 21(2):380-393, March 2006.

[17] Andersen Toke. Master Thesis: Radio Frequency Switch-Mode Power Supply. Master's thesis, Technical University of Denmark, 2010.

[18] Peter Kamby. Master Thesis: High Efficiency Radio Frequency Switchmode Power Supply for LED Applications. Master's thesis, Technical University of Denmark, 2011.

[19] Shanshan Lu; Yuqin Sun; Goldbeck, M.; Zimmanck, D.R.; Sullivan, C.R. 30-MHz Power Inductor Using Nano-Granular Magnetic Material. IEEE Power Electronics Specialists Conference, pages 1773-1776, June 2007.

[20] Sullivan, C.R.; Weidong Li; Prabhakaran, S.; Shanshan Lu. Design and fabrication of low-loss toroidal air-core inductors. IEEE Annual Power Electronics Specialists Conference, (38th):1754-1759, June 2007.

[21] Jizheng Qiu, Sullivan, C.R. . Inductor design for VHF tapped-inductor dc-dc power converters. Applied Power Electronics Conference and Exposition, (26th): 142 - 149, March 2011.

[22] Phinney, J.W.; Perreault, D.J.; Lang, J.H. Radio-Frequency Inverters With Transmission-Line Input Networks. IEEE Transactions on Power Electronics, 22(4):1154-1161, July 2007.

[23] Yehui Han; Cheung, G.; An Li; Sullivan, C.R.; Perreault, D.J. Evaluation of magnetic materials for very high frequency power applications. IEEE Power Electronics Specialists Conference, pages 4270-4276, 2008.

[24] Zirath, H.; Rutledge, D.; . An LDMOS VHF class E power amplifier using a high $\mathrm{Q}$ novel variable inductor. IEEE MTT-S International Microwave Symposium, Vol. 1:367-370, June 1999.

[25] M.K. Kazimierczuk. High-Frequency Magnetic Components. John Wiley \& Sons, 2009, ISBN: 9780470714539

[26] Bowman, W.C.; Balicki, F.T.; Dickens, F.T.; Honeycutt, R.M.; Nitz, W.A.; Strauss, W.; Suiter, W.B.; Ziesse, N.G. A resonant DC-toDC converter operating at 22 Megahertz. Applied Power Electronics Conference and Exposition, (3):3-11, 1988.

[27] Sagneri, A.D.; Anderson, D.I.; Perreault, D.J. Transformer synthesis for VHF converters. International Power Electronics Conference (IPEC) pages 2347-2353, June 2010.

[28] Warren, J.R. ; Rosowski, K.A. ; Perreault, D.J. Transistor Selection and Design of a VHF DC-DC Power Converter. IEEE Transactions on Power Electronics, Vol. 23(1):27-37, January 2008.

[29] Spiazzi, G. ; Mattavelli, P. ; Rossetto, L. Effects of Parasitic Components in High-Frequency Resonant Drivers for Synchronous Rectification MOSFETs. IEEE Transactions on Power Electronics, Vol. 23(4):20822092, July 2008.

[30] Kuang Sheng ; Yongxi Zhang ; Liangchun Yu ; Ming Su ; Zhao, J.H. . High-Frequency Switching of SiC High-Voltage LJFET. IEEE Transactions on Power Electronics, Vol. 24(1):271-277, January 2009.

[31] Pilawa-Podgurski, R.; Sagneri, A.D.; Rivas, J.M.; Anderson, D.I.; Perreault, D.J. Very-High-Frequency Resonant Boost Converters. IEEE Transactions on Power Electronics, 24(6):1654-1665, June 2009.

[32] Andersen, T.M. ; Christensen, S.K. ; Knott, A. ; Andersen, M.A.E. A VHF class E DC-DC converter with self-oscillating gate driver. Applied Power Electronics Conference and Exposition (APEC), pages 885-891, March 2011.

[33] Tatsuta, T. ; Ishitani, Y. ; Suetsugu, T. Gate power loss of class E amplifier with rectangular wave gate drive. TENCON 2010 IEEE Region 10 Conference, pages 1784-1787, November 2010.

[34] Rivas, J.M. ; Jackson, D. ; Leitermann, O. ; Sagneri, A.D. ; Yehui Han ; Perreault, D.J. . Design Considerations for Very High Frequency dc-dc Converters. Power Electronics Specialists Conference, pages 1-11, June 2006.

[35] M.K. Kazimierczuk and D. Czarkowski. Resonant Power Converters. John Wiley \& Sons, 2011, ISBN: 9780470905388.

[36] Liu, D.H.; Jiang, J.G. High frequency characteristic analysis of EMI filter in switch mode power supply (SMPS). Power Electronics Specialists Conference, Vol. 4:2039-2043, June 2002.

[37] Wang, C.P.; Liu, D.H.; Jiang Jianguo. Study of coupling effects among passive components used in power electronic devices. Power Electronics and Motion Control Conference, Vol. 3:1500-1504, August 2004.

[38] Liyu Yang; Bing Lu; Wei Dong; Zhiguo Lu; Ming Xu; Lee, F.C.; Odendaal, W.G. Modeling and characterization of a $1 \mathrm{KW}$ CCM PFC 
converter for conducted EMI prediction. Applied Power Electronics Conference and Exposition, Vol. 2:763-769, February 2004.

[39] Shuo Wang. Characterization and Cancellation of High-Frequency Parasitics for EMI Filters and Noise Separators in Power Electronics Applications. $\mathrm{PhD}$ thesis, Virginia Polytechnic Institute and State University, Blacksburg, Virgina, May 2005.

[40] Redl, Richard; Molnar, Bela; Sokal, Nathan O. Class E Resonan Regulated DC/DC Power Converters: Analysis of Operations, and Experimental Results at $1.5 \mathrm{MHz}$. IEEE Transactions on Power Electronics, PE-1(2):111-120, 1986

[41] P. Kamby; A. Knott, M. A.E. Andersen. Printed Circuit Board Integrated Toroidal Radio Frequency Inductors. 37th Annual Conference on IEEE Industrial Electronics Society - IECON 2011, October, 2012.

[42] Mickey Madsen. Master Thesis: Offline Very High Frequency Powe Converters. Master's thesis, Technical University of Denmark, 2012

[43] Kovacevic, Milovan; Knott, Arnold; Andersen, Michael A. E. Interleaved Self-Oscillating Class E Derived Resonant DC/DC Converters. International Conference on Electrical and Computer Systems, August 2012. 